\title{
Evidence of transient reconnection in the outflow jet of primary reconnection site
}

\author{
R. Wang ${ }^{1}$, R. Nakamura ${ }^{2}$, T. Zhang ${ }^{2}$, A. Du ${ }^{1}$, W. Baumjohann ${ }^{2}$, Q. Lu ${ }^{3}$, and A. N. Fazakerley ${ }^{4}$ \\ ${ }^{1}$ Key Laboratory of Ionospheric Environment, Institute of Geology and Geophysics, Chinese Academy of Sciences, \\ Beijing, China \\ ${ }^{2}$ Space Research Institute, Austrian Academy of Sciences, Graz, Austria \\ ${ }^{3}$ Department of Geophysics and Planetary Science, University of Science and Technology of China, Hefei, China \\ ${ }^{4}$ Mullard Space Science Laboratory, Surrey, UK
}

Correspondence to: R. Wang (rongsheng.wang@mail.iggcas.ac.cn)

Received: 28 March 2013 - Revised: 17 December 2013 - Accepted: 6 February 2014 - Published: 14 March 2014

\begin{abstract}
The precise mechanism for the formation of magnetic islands in the magnetotail and the subsequent evolution are still controversial. New investigations have provided the first observational evidence of secondary reconnection in the earthward outflow jet of primary reconnection in the magnetotail. The secondary reconnection takes place $38 c / \omega_{p i}$ earthward from the primary reconnection site and results in the birth of a magnetic island observed. This generation mechanism is different from the widely used model of multiple reconnection X-lines. The duration of the secondary reconnection was approximate one ion gyration period $(5 \mathrm{~s})$. The observations resemble recent numerical simulations where magnetic reconnection could spontaneously and transiently happen in the outflow jet, called secondary reconnection, which was used to explain the formation of the dipolarization fronts. Coincidentally, another magnetic island moving earthward passed through three satellites successively. By this chance we find the magnetic island was accelerated towards Earth with an acceleration of about $9 \mathrm{~km} \mathrm{~s}^{-2}$ at $-19 R_{\mathrm{E}}$ in the magnetotail.
\end{abstract}

Keywords. Magnetospheric physics (magnetotail; plasma sheet) - space plasma physics (magnetic reconnection)

\section{Introduction}

Bipolar signatures in the component of the magnetic field normal to the current sheet are frequently observed in the magnetotail (e.g. Sharma et al., 2008; Imber et al., 2011) and the interplanetary space (e.g. Lepping et al., 1990; Steed et al. 2008; Wang et al., 2011). They can be interpreted as plasmoids (e.g. Hones, 1977; Baumjohann et al., 1990), magnetic islands (Schindler, 1974), magnetic flux ropes (Birn et al., 1989; Slavin et al., 2003; Kiehas et al., 2012, 2013), night-side flux transfer events (Sergeev et al., 1992; Sormakov and Sergeev, 2008; Runov et al., 2008), or dipolarization fronts (Nakamura et al., 2002; Ohtani et al., 2004; Runov et al., 2009, 2011a, b; Schmid et al., 2011) in the magnetotail. These magnetic structures play an important role in mixing plasma and accelerating as well as transporting energetic particles (Nakamura et al., 2006; Retinò et al., 2008; Chen et al., 2008; Wang et al., 2010a, b; Fu et al., 2011; Wu et al., 2013). The birth of all such magnetic structures is thought to be closely associated with magnetic reconnection, but the precise details are different.

The model of multiple reconnection X-lines is generally used to explain the formation of plasmoids, magnetic islands, and magnetic flux ropes (Schindler, 1974; Lee and Fu, 1985; Slavin et al., 2003; Huang et al., 2012). In this model, magnetic reconnection occurs simultaneously at several points within the current sheet. Thus, such magnetic structures could be created between any two adjacent reconnection X-lines. Plasmoids are originally proposed to denote the closed magnetic loop between the near and distant neutral lines in the magnetotail (Hones, 1977), and are thereby driven tailward due to the pressure gradients and magnetic field tension. The later investigations confirm that the plasmoids can be observed in the mid-tail as well, with a smaller size (Ieda et al., 1998; Slavin et al., 1998), 10 Earth radii $\left(R_{\mathrm{E}}\right)$, and sometimes move earthward (e.g. Zong et al., 2007). In addition to the large scale plasmoids, the small scale $\left(\sim 0.5 R_{\mathrm{E}}\right)$ magnetic islands or magnetic flux ropes are 
investigated recently (e.g. Slavin et al., 2003; Deng et al., 2004; Henderson et al., 2006; Wang et al., 2012). This kind of small scale magnetic islands or magnetic flux ropes can be produced by the breakup of an extended electron current layer within the ion diffusion region of a single reconnection $\mathrm{X}$-line as predicted by numerical simulations (Daughton et al., 2006, 2011; Huang et al., 2011). Such small scale structures have been shown to exist near the centre of the ion diffusion region by Wang et al. (2010a, b). After their birth, they are ejected away from the ion diffusion region and propagate together with the ion bulk flow (Eastwood et al., 2007; Teh et al., 2010).

The term of "night side flux transfer events" was introduced by Sergeev et al. (1992) to indicate the impulsive events in the magnetotail with the similar feature to the dayside Flux Transfer Events (NFTEs). Contrary to the plasmoids and magnetic islands, the NFTEs have a locally open magnetic structure and are regarded as a result of fast pulsed reconnection (Runov et al., 2008; Sormakov and Sergeev, 2008). Because of the pulsed reconnection, the resulted burst outflow will compress the background magnetic field in both earthward and tailward sides of reconnection $\mathrm{X}$-line and bend the magnetic field towards the lobe region (e.g. Fig. 11d of Runov et al., 2008). As a consequence, an asymmetric bipolar (unipolar) $B_{z}$ signature will be observed if the spacecraft travels the NFTEs away from (near) the neutral sheet (Runov et al., 2008). Based on the formation mechanism, energetic electrons only appear in the reconnected magnetic tube whereas no energetic electrons distribute in the compressed background magnetic tubes, which have been verified recently (Runov et al., 2008; Sormakov and Sergeev, 2008).

Dipolarization fronts (DFs), generally embedded within the ion high speed flow, are characterised by a sharp increase of the northern magnetic field $\left(B_{z}\right)$ and preceded by a much smaller negative dip of $B_{z}$ (Nakamura et al., 2002; Ohtani et al., 2004; Runov et al., 2009; Runov et al., 2011a, b). The DFs have been extensively explored by recent Cluster and THEMIS observations. They, propagating earthward, show a relative stable structure for at least several minutes and energize particles to high energy in this process (Runov et al., 2009). They are directly related to magnetospheric substorm and make major contributions to substorm onset ground and space magnetic signatures also (e.g. Ge et al., 2012; Runov et al., 2011b). Numerical simulations suggest the spontaneous and transient magnetic reconnection could occur in the earthward outflow region of the tail-like configuration produced by the initially primary reconnection (Divin et al., 2007). The transient reconnection occurring in the outflow of primary reconnection X-line is called secondary reconnection (Sitnov et al., 2009). The scenario of secondary reconnection in the outflow of primary reconnection is believed to be the generation formation of the DFs (Sitnov et al., 2009; Runov et al., 2011b).

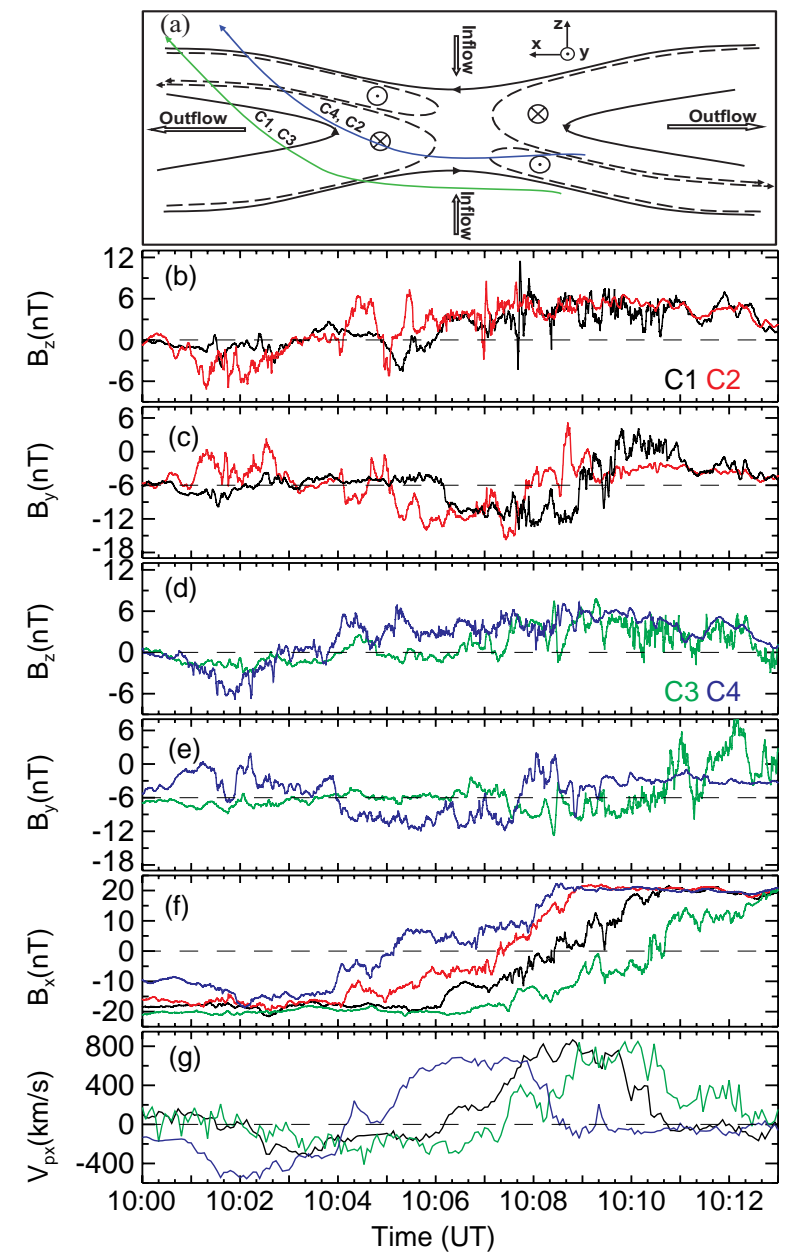

Fig. 1. Overview of the reconnection event in the magnetotail from 10:00 to 10:13 UT on 28 August 2002 is shown. From top to bottom, (a) an schematic illustrator of the ion diffusion region, (b) magnetic field component $B_{z}$ at $\mathrm{C} 1$ (black line) and C2 (red line), (c) $B_{y}$ at $\mathrm{C} 1$ and $\mathrm{C} 2$, (d) $B_{z}$ at $\mathrm{C} 3$ (green line) and $\mathrm{C} 4$ (blue line), (e) $B_{y}$ at $\mathrm{C} 3$ and $\mathrm{C} 4$, (f) $B_{x}$ from all four satellites, and (g) $x$ component of proton bulk flows $V_{\mathrm{p} x}$ from $\mathrm{C} 1, \mathrm{C} 3$, and $\mathrm{C} 4$ are presented.

In this letter, we studied three magnetic islands observed in the earthward side of one reconnection X-line in the nearEarth tail. The formation of such islands cannot be simply explained by the aforementioned model of multiple reconnection X-lines. The scenario of secondary reconnection in the outflow jet of primary reconnection, used to interpret the formation of the DFs, is more suitable to explain the formation of the observed islands.

\section{Observations and analysis}

We used magnetic field, ion plasma, and electric field data from the Flux Gate Magnetometer (FGM) (Balogh et al., 2001), the Cluster Ion Spectrometry (CIS/CODIF) (Rème et al., 2001), and the Electric Field and Wave Experiment 
(EFW) (Gustafsson et al., 2001) instruments, respectively. The electron energy-time spectrum data between $10 \mathrm{eV}$ and $23 \mathrm{keV}$ and the high energy ( $>40 \mathrm{keV}$ ) electron flux data are taken from the Plasma Electron And Current Experiment (PEACE) (Johnstone et al., 1997) and the Research with Adaptive Particle Imaging Detectors (RAPID) (Wilken et al., 2001), respectively. Figure 1 shows an overview of the reconnection event observed at $\sim 19 R_{\mathrm{E}}$ in the magnetotail. Figure 1a represents the schematic illustrator for this event. $B_{z}$ and $B_{y}$ at $\mathrm{C} 1$ and $\mathrm{C} 2(\mathrm{C} 3$ and $\mathrm{C} 4)$ are presented in Fig. $1 \mathrm{~b}$ and $\mathrm{c}\left(1 \mathrm{~d}\right.$ and e), respectively. $B_{x}$ at four satellites and $x$ component of the high speed bulk flows at $\mathrm{C} 1, \mathrm{C} 3$, and $\mathrm{C} 4$ are shown in Fig. If and g, respectively. The black, red, green, and blue colours correspond to $\mathrm{C} 1, \mathrm{C} 2, \mathrm{C} 3$ and $\mathrm{C} 4$, respectively. The data is displayed in Geomagnetic Solar Magnetospheric (GSM) coordinates. The minimum variance analysis (MVA) was applied to this whole interval (Sonnerup and Scheible, 1998), the local current coordinates is very close to the GSM coordinates. So, the GSM coordinates is used through this paper except otherwise stated (Wang et al., 2012). In this interval, Cluster crossed a reconnection diffusion region from tailward to earthward and then passed through its earthward part from south to north (Fig. 1a). The ion diffusion region is identified based on the highly correlated reversals of $B_{z}$ and $V_{\mathrm{p} x}$, the clear quadrupolar Hall magnetic structure (Fig. 1c of Wang et al., 2012), and energetic particles (not shown here). More details could be found in Wang et al. (2012). During the earthward crossing of the ion diffusion region, the north-south asymmetry caused by the addition of guide field is recognised (Wang et al., 2012). The effect of a strong guide field on magnetic reconnection has been reported by Nakamura et al. (2008). Here, we primarily concentrate on three bipolar magnetic signatures with sign change observed by $\mathrm{C} 2$ and $\mathrm{C} 1$ in the central plasma sheet (10:07-10:09 UT, Fig. 1b). The reconnection was continuing while the bipolar signatures were observed from 10:04 to 10:10 UT. So, the northward reconnected magnetic field component $B_{z}$ was persistently observed (Fig. 1b and d) and the average value was about $4 \mathrm{nT}$.

An expanded view of the three bipolar signatures is displayed in Fig. 2. From top to bottom, (a) electron densities and (b-d) three components as well as (e) magnitude of magnetic field at $\mathrm{C} 1$ (black) and $\mathrm{C} 2$ (red), (f) plasma beta and ion pressure at $\mathrm{C} 1$, and electron energy-time spectra at $(\mathrm{g}) \mathrm{C} 2$ and (h) $\mathrm{C} 1$ are presented. The three bipolar signatures are named Fr1, Fr2 and Fr3, respectively, and the three vertical dashed lines within the bipolar signatures correspond to the points of $B_{z}=0$. It can be seen that $B_{z}$ rotated from south to north for each perturbation. All three $B_{z}$ perturbations exhibited asymmetric feature with the negative amplitude smaller than the positive amplitude. The plasma density had a significant enhancement as well at all three $B_{z}$ perturbations, even an evident density peak at Fr1 and Fr3. The magnitudes of the magnetic field had local maxima at $\mathrm{Fr} 1$ and $\mathrm{Fr} 2$ also. $B_{y}$ was always very strong $(\sim 12 \mathrm{nT})$ between 10:06:40 and

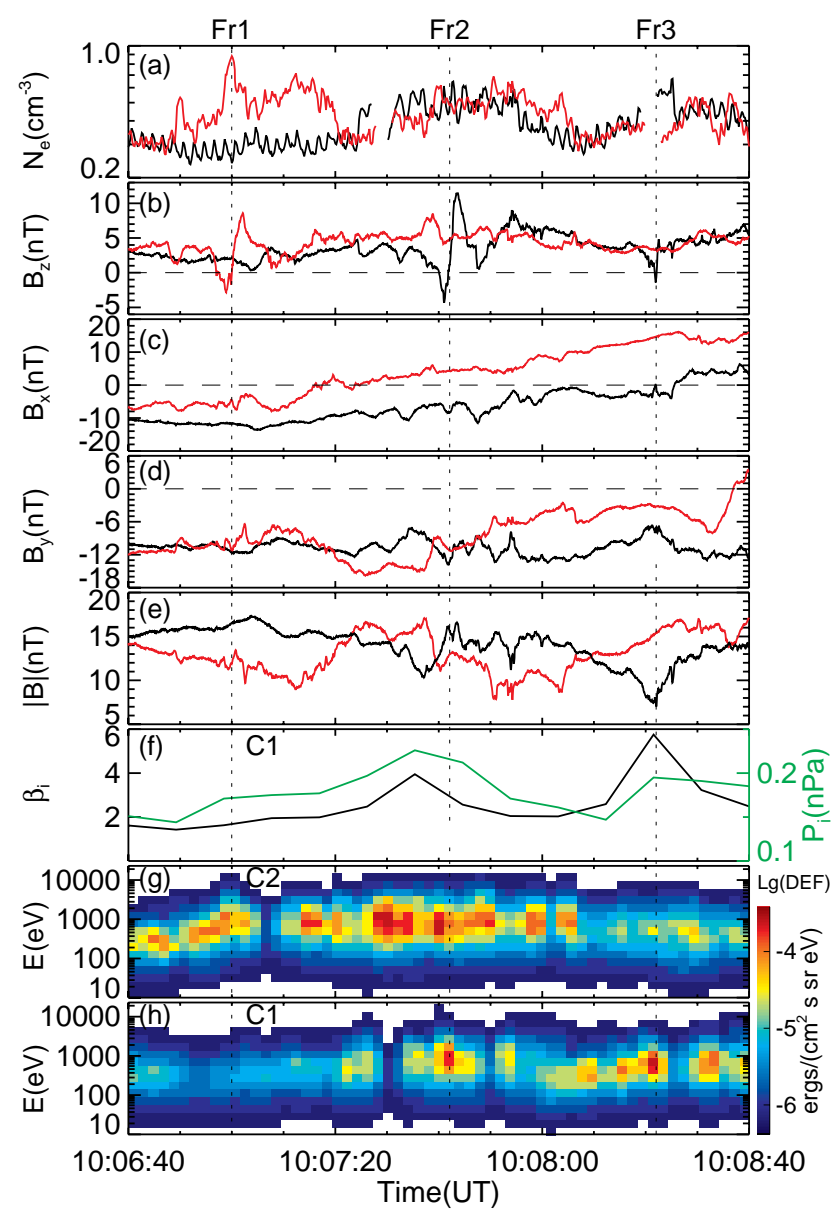

Fig. 2. (a) electron density derived from the spacecraft potential, magnetic field components (b) $B_{z}$, (c) $B_{x}$, and (d) $B_{y}$, and (e) magnetic field magnitude $|\boldsymbol{B}|$ at $\mathrm{C} 1$ and $\mathrm{C} 2$, (f) ion beta (black) and ion pressure (green), and electron energy-time spectra at (g) $\mathrm{C} 2$ and (h) C1 during the interval 10:06:40-10:08:40 UT are presented.

10:08:40 UT and displayed a small localised peak within Fr1 and Fr2. Based on these observations, the measured three bipolar signatures are consistent with the observations of magnetic islands or magnetic flux rope-like moving earthward (Slavin et al., 2003; Wang et al., 2012). Moreover, the electron fluxes were intensified in all three bipolar signatures. As for Fr1, the fluxes of electrons between $300 \mathrm{eV}$ and $4 \mathrm{keV}$ (Fig. 2g) were significantly enhanced while no flux enhancement was observed by $\mathrm{C} 1$ (Fig. 1h) grazing Fr1 from its southern edge. The high energy electron fluxes $(\sim 40.7 \mathrm{keV})$ show a similar distribution (Fig. $5 \mathrm{c}$ and d). The enhancement of the electron fluxes from $300 \mathrm{eV}$ to $40 \mathrm{keV}$ indicates electrons are trapped within the magnetic structure. In other words, it should not be the night side flux transfer event but a magnetic island or magnetic flux rope-like. The similar enhancement of the electron fluxes are also measured inside $\mathrm{Fr} 2$ and Fr3, as shown in Figs. $2 \mathrm{~h}$ and $5 \mathrm{~g}$ and $\mathrm{h}$. All three bipolar signatures are helical magnetic structures and interpreted as 

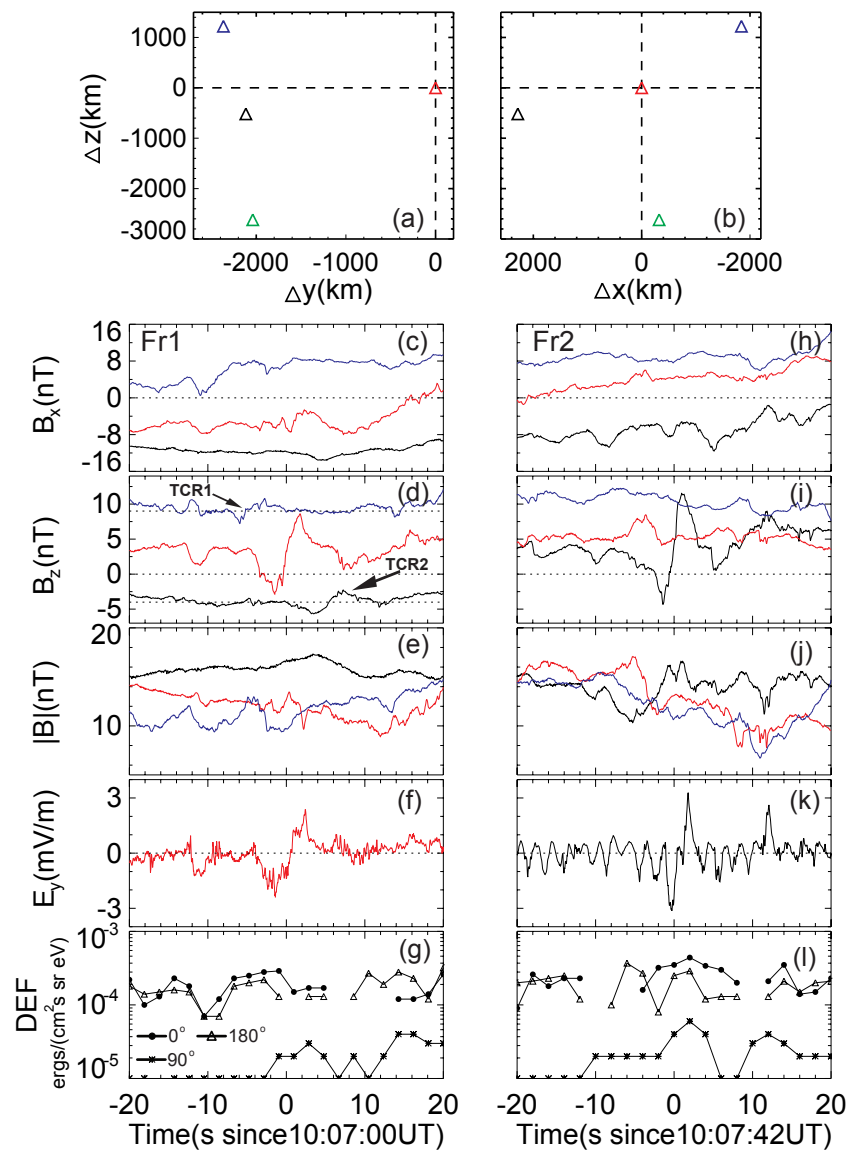

Fig. 3. Relative position of the four Cluster satellites $(\mathrm{C} 1, \mathrm{C} 2, \mathrm{C} 3$, and C4) at 10:07 UT in the (a) $z-y$ plane and (b) $z-x$ plane of the GSM coordinates are shown. Magnetic field, electric field and electron angle distribution data around Fr1 and Fr2 are displayed in (c)(g) and (h)-(l), respectively. For Fr1, magnetic field component (c) $B_{x}$ and (d) $B_{z}$, and (e) magnetic field magnitude $|\boldsymbol{B}|$ at $\mathrm{C} 1, \mathrm{C} 2$, and C4, (f) electric field $E_{y}$ in the spacecraft spin coordinates from $\mathrm{C} 2$, and (g) electron differential energy fluxes from $\mathrm{C} 2$ at three directions $\left(0^{\circ}, 90^{\circ}\right.$, and $\left.180^{\circ}\right)$ are presented. The energy of the electron fluxes is between $300 \mathrm{eV}$ and $6 \mathrm{keV}$. In order to separate the three curves in (d), the blue and black curves are shifted up and down $6 \mathrm{nT}$, respectively. Please note that both blue and black curves were above zero horizontal dashed line $\left(B_{z}>0\right)$. The data around $\mathrm{Fr} 2$ are shown in the same format in (h)-(l). Because Fr2 were observed by $\mathrm{C} 1, E_{y}$ and electron fluxes at $\mathrm{C} 1$ are represented in (k) and (l), respectively. Again, the blue curve in (i) are moved up 6 nT. The small sine fluctuations of $E_{y}$ in (k) are formed due to the failure of probe 1 onboard C1. The data gap in Fig. 3g and 1 means no data collected.

magnetic islands. In the next section, we will mainly analyse the first two observed magnetic structures Fr1 and Fr2.

The relative positions of the four satellites in the $y-z$ and $x-z$ planes at 10:07 UT are shown in Fig. 3a and b, respectively. The data associated with Fr1 and Fr2 are shown in Fig. $3 \mathrm{c}-\mathrm{g}$ and $\mathrm{h}-1$, respectively. Figure $3 \mathrm{c}-\mathrm{g}$ present magnetic field (c) $B_{x}$, (d) $B_{z}$ and (e) $|\boldsymbol{B}|$ at $\mathrm{C} 1, \mathrm{C} 2$ and C4, respectively,
Table 1. Results from MVA applied to C2 magnetic field between 10:06:54 and 10:07:06 UT.

\begin{tabular}{lll}
\hline Fr1 & Eigenvalue & Eigen vector \\
\hline Minimum (L) & 0.55 & $(-0.19,0.97,-0.16)$ \\
Intermediate (M) & 1.14 & $(0.96,0.14,-0.26)$ \\
Maximum (N) & 8.86 & $(0.23,0.20,0.95)$ \\
\hline
\end{tabular}

(f) the electric field $E_{y}$ at $\mathrm{C} 2$, and (g) electron differential energy fluxes in parallel $\left(0^{\circ}\right)$, perpendicular $\left(90^{\circ}\right)$, and antiparallel $\left(180^{\circ}\right)$ directions at $\mathrm{C} 2$, around the Fr1. Figure $3 \mathrm{~g}-1$ show the data around $\mathrm{Fr} 2$ observed by $\mathrm{C} 1$ in the same format. Therefore, the electric field $E_{y}$ in Fig. $3 \mathrm{k}$ and electron fluxes in Fig. 31 are taken from $\mathrm{C}$. In order to separate the three curves in Fig. 3d, the blue and black curves are shifted up and down $6 \mathrm{nT}$, respectively. The most used approach for the inference of the orientation of the magnetic island/magnetic flux rope is the minimum variance analysis (MVA) method. The MVA method was individually applied to the magnetic field at $\mathrm{C} 2$ and $\mathrm{C} 1$ to obtain the orientations of the magnetic structures Fr1 and Fr2. As has been pointed out by Xiao et al. (2004), the axis of the non-force free magnetic flux rope can either be in the $\mathrm{L}$ direction, or in the $\mathrm{M}$ direction depending on the spacecraft trajectory relative to the core region. For $X<2(2<X<5)$, the L (M) direction from MVA represents the axis of the magnetic flux rope, where $X$ denotes the closest distance between the spacecraft trajectory and the axis. In this event, the Lorentz forces around both ropes Fr1 and Fr2 are large (Fig. 5b and f). Hence, they are non-force free flux ropes. The MVA results for Fr1 and Fr2 are displayed in Tables 1 and 2, respectively. The three components of magnetic field in the LMN coordinates are presented in Fig. 5a and e. The bipolar signatures are still very clear in the LMN coordinates.

The $B_{x}$ average value was about $-5 \mathrm{nT}$ (Fig. 2c) while the spacecraft $\mathrm{C} 2$ encountered Fr1. Namely, the spacecraft crossed its central region. So, the orientation of Fr1 was mainly along the $\mathrm{L}$ direction, $(-0.19,0.97,-0.16)$, close to the $y$ axis in the GSM coordinates. As for Fr2, The $B_{x}$ average value was about $-9 \mathrm{nT}$ while $\mathrm{C} 1$ crossed it. Contrary to the results from Fr1, the $\mathrm{L}$ direction corresponds to the $x$ direction in the GSM coordinates. Thus, it is impossible that the orientation of Fr2 was mainly along the $x$ direction. So, we interpret the $\mathrm{M}$ direction was the orientation of the magnetic flux rope $\mathrm{Fr} 2$, i.e. the spacecraft trajectory belonged to $2<X<5$. Based on the analysis, the orientations of the two magnetic flux ropes were both mainly along the $y$ direction of the GSM coordinates. So, we chose the GSM coordinates to describe the ropes finally.

It is evident from $B_{x}$ (Fig. 3c) that as Fr1 was observed by $\mathrm{C} 2$ in the Southern Hemisphere $\left(B_{x} \approx-5 \mathrm{nT}\right), \mathrm{C} 4$ and $\mathrm{C} 1$ were situated in the Northern and more Southern Hemisphere, respectively ( $B_{x} \approx 7 \mathrm{nT}$ at $\mathrm{C} 4$ and $-12 \mathrm{nT}$ at $\mathrm{C} 1$ ). 
Table 2. Results from MVA applied to $\mathrm{C} 1$ magnetic field between 10:07:38 and 10:07:46 UT.

\begin{tabular}{lll}
\hline Fr2 & Eigenvalue & Eigen vector \\
\hline Minimum (L) & 1.29 & $(0.93,0.35,-0.14)$ \\
Intermediate $(\mathrm{M})$ & 3.44 & $(-0.36,0.93,-0.09)$ \\
Maximum (N) & 14.94 & $(0.10,0.13,0.99)$ \\
\hline
\end{tabular}

This is in accordance to the spatial location of the three satellites in $x-z$ plane shown in Fig. 3b. The separations in $z$ direction between $\mathrm{C} 4$ and $\mathrm{C} 2$ and between $\mathrm{C} 2$ and $\mathrm{C} 1$ were about $1221 \mathrm{~km}$ and $516 \mathrm{~km}$ at the moment, respectively. $\mathrm{C} 4$ was located farthest away from Earth while $\mathrm{C} 1$ was closest to Earth (Fig. 3b). C2 was located between $\mathrm{C} 1$ and $\mathrm{C} 4$. It is evident from Fig. 3d that, before and after Fr1, C4 and $\mathrm{C} 1$ both measured one south-then-north $B_{z}$ perturbation at $\sim-6 \mathrm{~s}$ and $\sim 6 \mathrm{~s}$ since 10:07:00 UT, respectively. For both small perturbations, magnetic field was intensified (Fig. 3e). These two small $B_{z}$ bipolar signatures observed by $\mathrm{C} 4$ and $\mathrm{C} 1$ just before and after Fr1 are in good agreement with the observation of travelling compression region (TCR) (Slavin et al., 1984) and called TCR 1 and TCR 2 respectively. The south-then-north perturbations suggest they are caused by an earthward moving structure. While $\mathrm{C} 2$ observed the leading edge of Fr1, C4 detected the trailing edge of the TCR1. While $\mathrm{C} 2$ entered into the trailing part of Fr1, $\mathrm{C} 1$ began to observe the leading edge of the TCR2. That is to say that at least two satellites measured the perturbation simultaneously for the whole travelling. So, we interpret all the three perturbations in Fig. 3d are caused by one magnetic flux ropes moving earthward. As Fr1 was moving earthward, only $\mathrm{C} 2$ penetrated into the flux rope while $\mathrm{C} 4$ and $\mathrm{C} 1$ just passed separately its northern and southern edges. A schematic is shown in the top panel of Fig. 4. Accordingly, the height of the flux rope Fr1 was comparable to the distance between $\mathrm{C} 4$ and $\mathrm{C} 1$ in $z$ direction $(1737 \mathrm{~km})$.

Using the "time of flight" of the flux ropes across the three satellites, we can estimated the Fr1 velocity in $x$ direction. The times corresponding to the minimum values of the bipolar $B_{z}$ signatures were used. The average velocity of Fr1 between $\mathrm{C} 4$ and $\mathrm{C} 2$ is $V_{4,2}=x_{4,2} / t_{4,2}=1839.4 / 4.42 \approx$ $416 \mathrm{~km} \mathrm{~s}^{-1}, x_{4,2}, t_{4,2}$ are the distance and time delay between $\mathrm{C} 4$ and C2. Similarly, the average velocity of Fr1 between $\mathrm{C} 2$ and $\mathrm{C} 1$ was $V_{2,1}=x_{2,1} / t_{2,1}=2286.3 / 5.0 \approx 457 \mathrm{~km} \mathrm{~s}^{-1}$. The average velocity of Fr1 between $\mathrm{C} 2$ and $\mathrm{C} 1$ was larger than that between $\mathrm{C} 4$ and $\mathrm{C} 2$. It might mean that the magnetic flux ropes did not move earthward evenly. Assuming it was uniformly accelerated motion, the acceleration was assessed, $a=2 \times\left(V_{2,1}-V_{4,2}\right) /\left(t_{4,2}+t_{2,1}\right) \approx 9 \mathrm{~km}^{-2}$. This acceleration of magnetic island has never been obtained by the spacecraft before. Using the times of the maxima of the bipolar $B_{z}$ signatures, we get the similar conclusion and the acceleration was about $7 \mathrm{~km} \mathrm{~m}^{-2}$. At $0 \mathrm{~s}$ in Fig. 3d, C1 was encountering

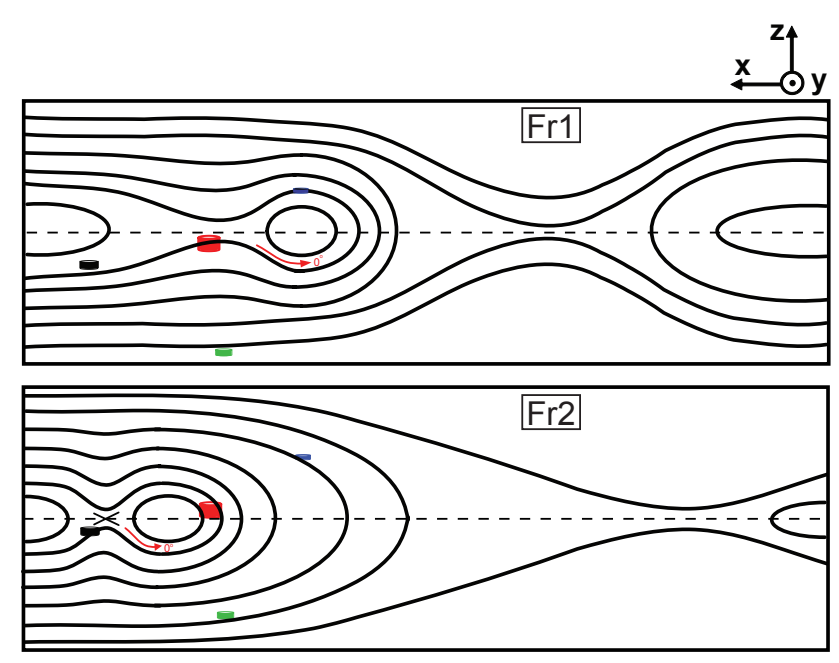

Fig. 4. Schematic illustrators for the two magnetic flux ropes Fr1 and $\mathrm{Fr} 2$ are presented. The four coloured columns correspond to the four satellites C1 (Black), C2 (Red), C3 (Green), and C4 (Blue). The different sizes of the spacecraft represent their displacements in $y$ direction. The red lines with arrow denote the electron flow parallel to magnetic field lines.

the leading edge while $\mathrm{C} 4$ was right staying in the trailing edge of Fr1. Hence, the Fr1 scale in $x$ direction was comparable to the separation between $\mathrm{C} 4$ and $\mathrm{C} 1$ in $x$ direction $(4126 \mathrm{~km})$. Then, the aspect ratio of Fr1 was about 0.4. Based on the analysis above, Fr1 was squeezed in $z$ direction and might be accelerated towards Earth with an acceleration of about $9 \mathrm{~km} \mathrm{~s}^{-2}$. This conclusion is based on the assumption that the minimum/maximum values of the bipolar $B_{z}$ signature make up a planar structure in $y-z$ plane or a symmetric structure between the Northern and Southern Hemispheres. Obviously, the assumption will cause an error of the calculation of the acceleration. However, the consistency between the estimations of the the acceleration and the force exerted on the magnetic structure Fr1 (discussed later) indicates the calculation of the acceleration is basically right.

After the observation of Fr1, C2 stayed in the central plasma sheet $\left(\left|B_{x}\right|<5 \mathrm{nT}\right)$ for about $40 \mathrm{~s}$ (Fig. 2c). Meanwhile, $\mathrm{C} 1$ in the Southern Hemisphere was approaching the central plasma sheet. During this process, $\mathrm{C} 2$ did not observe any other flux ropes again (Fig. 2b). The unexpected finding, however, is that $\mathrm{C} 1$ observed another magnetic flux rope of Fr2 moving earthward at about 10:07:40 UT. $B_{x}$ at C1 was about -9 nT while $\mathrm{Fr} 2$ was observed whereas $\left|B_{x}\right|$ at $\mathrm{C} 2$ was less than $5 \mathrm{nT}$ between $\mathrm{Fr} 1$ and $\mathrm{Fr} 2$. In other words, $\mathrm{C} 2$ was closer to the central plasma sheet than $\mathrm{C} 1$. If this flux rope was really ejected from the primary reconnection $\mathrm{X}$-line in the tailward side of both satellites, it should have been observed firstly by $\mathrm{C} 2$ and then $\mathrm{C} 1$. One explanation for this observation of $\mathrm{Fr} 2$ is that the observed $\mathrm{Fr} 2$ was a night side flux transfer event with a localised open structure. 
Thus, $\mathrm{C} 1$ away from the neutral sheet detected a bipolar $B_{z}$ signature whereas $\mathrm{C} 2$ near the neutral sheet measured the unipolar $B_{z}$ enhancement at about $-4 \mathrm{~s}$ since 10:07:42 UT (Fig. 3i), like the observation reported by Runov et al. (2008). If so, however, the amplitude of $B_{z}$ variation observed by $\mathrm{C} 2$ and $\mathrm{C} 1$ should be nearly equal. The fact is that the amplitude of $B_{z}$ variation at $\mathrm{C} 2$ was about $5 \mathrm{nT}$ while the amplitude observed by $\mathrm{C} 1$ was about $15 \mathrm{nT}$ (Fig. 3i). On the other hand, if Fr2 was really one night side flux transfer event, C2 would observe a sharp increase of energetic electrons in the reconnected magnetic flux tubes, i.e. the $B_{z}$ enhancement region. However, no significant intensification of electron fluxes from low energy (Fig. 2g) to high energy (Fig. 5h) was detected there. The flux bulge resulting from time-dependent reconnection could be used also to explain the observed Fr2 (e.g. Beyene et al., 2011). In this scenario, the spacecraft away from (within) the central plasma sheet will observe an asymmetric bipolar $B_{z}$ signature (a unipolar enhancement of $B_{z}$ ), and no core magnetic field is expected inside the flux bulge. Moreover, because the flux bulge is formed inside the plasma sheet, the plasma characteristic in the plasma sheet is contained within the bulge. However, there was a clear core field above the ambient field (Fig. 2d) within the observed magnetic structure Fr2. The electron fluxes from $100 \mathrm{eV}$ to $4 \mathrm{keV}$ (Fig. 2h) were enhanced within the Fr2. These measurements within the Fr2 are inconsistent with the flux bulge. Accompanying with the magnetic island Fr2, electric field component $E_{y}$ reversed also from negative to positive. This electric field component $E_{y}$ should be the convection electric field due to the earthward motion of magnetic island. According to the analysis above, we interpret that the magnetic structure $\mathrm{Fr} 2$ was created and centred between $\mathrm{C} 2$ and $\mathrm{C} 1$ and then moved earthward. Consequently, only $\mathrm{C} 1$ in the earthward side of $\mathrm{C} 2$ detected the flux rope while $\mathrm{C} 2 \mathrm{did}$ not observe any bipolar signature. Instead of the bipolar $B_{z}$ signature observed by $\mathrm{C} 1, \mathrm{C} 2$ observed a significant increase of $B_{z}$ and $|\boldsymbol{B}|$ at about $-4 \mathrm{~s}$ since 10:07:04 UT (Fig. 3i and j). The duration of the increase was about 5 seconds, approximately one proton gyration period. Such an increase should be directly related to the formation mechanism of the flux rope.

\section{Discussions}

Magnetic flux ropes/islands are generally embedded in and move together with high-speed flows in the magnetotail (Slavin et al., 2003; Nakamura et al., 2006; Lui et al., 2007; Wang et al., 2012). The speed is roughly a few hundred of kilometres per second. By the Geotail observations in the near-tail, Slavin et al. (2003) figured out that most of the earthward moving flux ropes can be described as force-free flux ropes, i.e. $\boldsymbol{J}=\alpha \boldsymbol{B}, \alpha$ is a constant quantity. Recent Cluster multi-point measurements found that the Lorentz force $\boldsymbol{J} \times \boldsymbol{B}$ around magnetic flux ropes is significant (Henderson
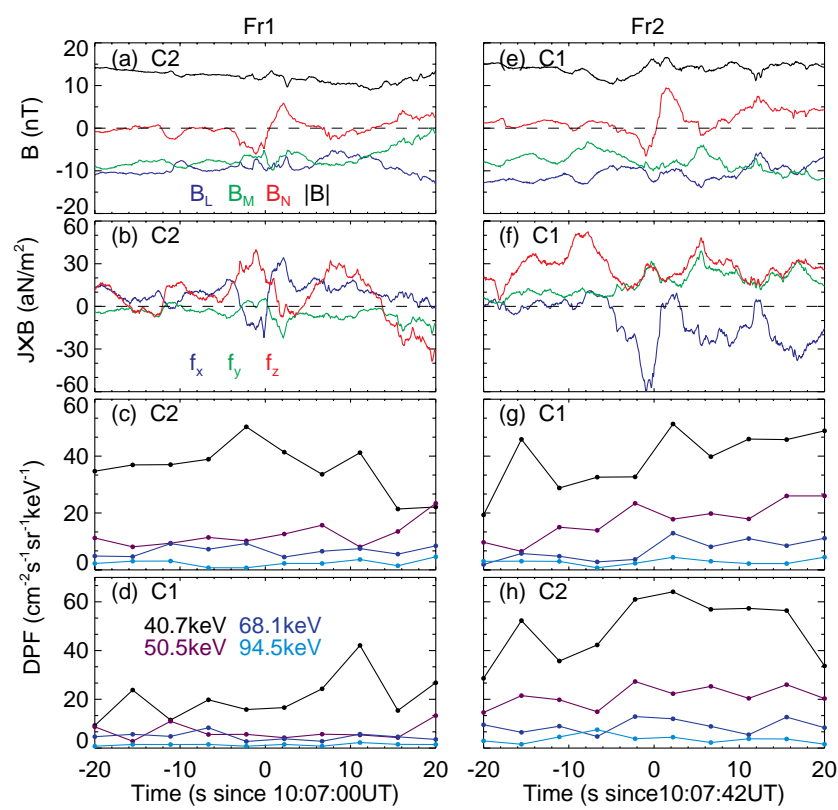

Fig. 5. (a) the magnetic field in the local minimum variance coordinates (LMN), (b) the three components of the Lorentz force $\boldsymbol{J} \times \boldsymbol{B}$ in GSM coordinates, and the high energy electron fluxes at (c) C2 and (d) $\mathrm{C} 1$ around Fr1 are presented. (e-h) show the similar data around $\mathrm{Fr} 2$ in the same format.

et al., 2006; Zong et al., 2007; Wang et al., 2010a, b). Using the same method, Lui et al. found that $x$ component of the Lorentz force directed earthward initially and then tailward while one flux rope was moving tailward (Lui et al., 2007). In our event, the Lorentz force was estimated also. Figure $5 \mathrm{a}-\mathrm{d}(\mathrm{e}-\mathrm{h})$ show magnetic field vector in the LMN coordinates, the Lorentz force components in the GSM coordinates, and energetic electron fluxes around Fr1 (Fr2). The current density $\boldsymbol{J}$ was estimated from the magnetic field at the four satellites by the Curlometer technique (Chanteur and Harvey, 1998) whereas all the flux ropes were observed by single satellite. So, the two variables $\boldsymbol{J}$ and $\boldsymbol{B}$ did not match up very well when we calculated the Lorentz force around the flux ropes, which will cause relatively large errors of the estimated Lorentz force. During the interval (10:06:40 10:08:40 UT) that we are interested in, the four satellites just crossed the neutral sheet of the plasma sheet. So, the estimated current is basically the cross-tail current. C2 crossed the centre of Fr1 $\left(B_{x} \sim-5 \mathrm{nT}\right)$, therefore the Lorentz force around Fr1 is basically reliable and increased around it. The $x$ component of the Lorentz force $f_{x}$ changed sign from negative (tailward) in the leading part to positive (earthward) in the trailing part around the Fr1. The average force in the leading part was smaller than that in the trailing part. Therefore, the integrated Lorentz force exerted on the whole Fr1 in $x$ component was still directed earthward. Fr1 was observed in the earthward outflow jet and the plasma pressure gradient should direct earthward also, although the ion plasma data 
were unavailable at $\mathrm{Fr} 1$ observed by $\mathrm{C} 2$. So, the magnetic structure was accelerated towards Earth, which is in accordance to the calculation of the acceleration.

Recent numerical simulations suggest the spontaneous and transient magnetic reconnection could occur in the outflow region of the tail-like configuration produced by the initially primary X-line (Divin et al., 2007). This kind of magnetic reconnection in the outflow region of primary reconnection $\mathrm{X}$-line is called secondary reconnection (Sitnov et al., 2009). In our event, the earthward moving magnetic island $\mathrm{Fr} 2$ was just observed by $\mathrm{C} 1$ in the earthward side of primary reconnection $\mathrm{X}$-line whereas $\mathrm{C} 2$, closer to the primary $\mathrm{X}$-line and situated in the central plasma sheet, did not detect it. The observation strongly indicates the occurrence of secondary reconnection in the outflow between $\mathrm{C} 2$ and $\mathrm{C} 1$. Consequently, a magnetic island would be created and centred between $\mathrm{C} 2$ and $\mathrm{C} 1$. While the secondary reconnection was proceeding, it will temporarily block the way of the earthward moving reconnected magnetic flux tubes from the primary reconnection X-line, which will result in a further pileup of $B_{z}$ and $|\boldsymbol{B}|$ in the tailward of the flux rope. Thus, the intensification of $B_{z}$ and $|\boldsymbol{B}|$ were observed at $\mathrm{C} 2$ tailward of the secondary reconnection, as shown in the bottom panel of Fig. 4. As the continuing increase of $B_{z}$ and $|\boldsymbol{B}|$, the secondary reconnection would cease and the resulted flux rope would move earthward. Hence, the duration of the $B_{z}$ enhancement $(5 \mathrm{~s})$ might be the period of the secondary reconnection.

From the electron differential energy fluxes in three $\left(0^{\circ}\right.$, $90^{\circ}, 180^{\circ}$ ) directions shown in Fig. 31, the fluxes parallel to magnetic field are higher than those in antiparallel and perpendicular directions within the flux ropes while, out of the flux ropes, the fluxes in parallel and antiparallel directions became nearly equal. The electron flow parallel to magnetic field at $\mathrm{C} 1$ is another evidence for the occurrence of secondary reconnection. Because of the secondary reconnection, electrons are energized and then move away along the magnetic field, as the red line with arrow in Fig. 4. Additionally, although the fluxes in the perpendicular direction are significantly lower than other directions, they display a clear peak within the flux ropes. An apparent enhancement of electron fluxes at $90^{\circ}$ within flux ropes has been reported also by Retinò et al. (2008). The relation between the energetic electron enhancement and the normal magnetic field $\left(B_{z}\right)$ enhancement has been established (Imada et al., 2007; Wang et al., 2008). Their acceleration mechanism remains to be understood. The whole ion diffusion region was moving tailward with a velocity of $-56.5 \mathrm{~km} \mathrm{~s}^{-1}$ (Wang et al., 2012). So, the distance between the centre of Fr2 and the primary X-line could be roughly estimated by the velocity and the time delay. The distance was about $56.5 \mathrm{~km} \mathrm{~s}^{-1} \times 280 \mathrm{~s} \approx 38 c / \omega_{p i}\left(c / \omega_{p i}\right.$ : ion inertial length, $\sim 416 \mathrm{~km}$ for $N=0.3 \mathrm{~cm}^{-3}$ ). That means the secondary reconnection could happen $38 c / \omega_{p i}$ earthward away from the primary reconnection.
After $40 \mathrm{~s}$ of $\mathrm{Fr} 2, \mathrm{C} 1$ in the central plasma sheet $\left(B_{x} \approx\right.$ $0 \mathrm{nT}$ ) observed the third flux rope Fr3 (Fig. 2b). At this time, $\mathrm{C} 2$ was no longer in the central plasma sheet $\left(B_{x} \approx 10 \mathrm{nT}\right)$. So, we cannot confirm where the flux rope of Fr3 is created. However, the similar characteristic of the three flux ropes imply that they might be created by one same mechanism. In other words, the secondary reconnection could occur multiple times during single primary reconnection. It seems also that, in the process of primary reconnection, the location of secondary reconnection occurred farther and farther away from the primary reconnection $\mathrm{X}$-line. The underlying reason is still unclear.

By multi-point simultaneous observations, we provide the first evidence of secondary reconnection here. Due to its transient nature, we know little about the secondary reconnection itself at present. More theoretical and experimental efforts are needed. After the birth, the earthward moving magnetic island is ejected toward Earth. Inevitably, it will decelerate due to the persistent increase of the pressure gradient force directed tailward. Nevertheless, how it evolves before it decelerates is still open. By multiple point simultaneous observations, we found that the magnetic island was being accelerated towards Earth at $-19 R_{\mathrm{E}}$ in the magnetotail and the acceleration is about $9 \mathrm{~km} \mathrm{~s}^{-2}$.

\section{Summary}

We analysed three asymmetric magnetic islands in the earthward outflow of primary reconnection X-line in detail. The birth of the island cannot be simply explained by the classic multiple reconnection X-line model. By Cluster multipoint simultaneous observations, we confirm that the scenario of spontaneous reconnection in the outflow of primary reconnection X-line is the candidate for the birth of magnetic island. The evidence of the occurrence of spontaneous reconnection is provided as well, e.g. the accelerated electron flow, the enhancement of magnetic field between two $\mathrm{X}$-lines. Multiple asymmetric islands suggest the secondary reconnection might occur several times during single primary reconnection. Its location could extend as far as $38 c / \omega_{p i}$ and farther away from primary reconnection X-line. After the birth, the magnetic island was accelerated towards Earth at $-19 R_{\mathrm{E}}$, and the acceleration is about $9 \mathrm{~km} \mathrm{~s}^{-2}$.

Acknowledgements. We appreciate the helpful discussion with V. Sergeev and M. I. Sitnov. All Cluster data other than the PEACE data are obtained from the ESA Cluster Active Archive. We thank the FGM, CIS, and EFW instrument teams and the ESA Cluster Active Archive. This work is supported by the National Science Foundation of China (NSFC) grants (41104092, 41174122 and 41274144) and China Postdoctoral Science Foundation Funded Project (2011M500030 and 2012T50133). This work is partly supported by the Austrian Science Fund (FWF) I429-N16.

Topical Editor M. Gedalin thanks three anonymous referees for their help in evaluating this paper. 


\section{References}

Balogh, A., Carr, C. M., Acuña, M. H., Dunlop, M. W., Beek, T. J., Brown, P., Fornacon, K.-H., Georgescu, E., Glassmeier, K.H., Harris, J., Musmann, G., Oddy, T., and Schwingenschuh, K.: The Cluster Magnetic Field Investigation: overview of in-flight performance and initial results, Ann. Geophys., 19, 1207-1217, doi:10.5194/angeo-19-1207-2001, 2001.

Baumjohann, W., Paschmann, G., and Luhr, H.: Characteristics of high speed ion flows in the plasma sheet, J. Geophys. Res., 95, 3801, doi:10.1029/JA095iA04p03801, 1990.

Beyene, S., Owen, C. J., Walsh, A. P., Forsyth, C., Fazakerley, A. N., Kiehas, S., Dandouras, I., and Lucek, E.: Cluster observations of a transient signature in the magnetotail: implications for the mode of reconnection, Ann. Geophys., 29, 2131-2146, doi:10.5194/angeo-29-2131-2011, 2011.

Birn, J., Hesse, M., and Schindler, K.: Filamentary structure of a three-dimensional plasmoid, J. Geophys. Res., 94, 241-251, 1989.

Chanteur, G. and Harvey, C.: Spatial interpolation for four spacecraft: Application to magnetic gradients, in: Analysis Methods for Multi-Spacecraft Data, edietd by: Paschmann, G. and Daly, P., 349-369, ESA, Noordwijk, 1998.

Chen, L. J., Bhattacharjee, A., Puhl-Quinn, P. A., Yang, H., Bessho, N., Imada, S., Muehlbachler, S., Daly, P. W., Lefebvre, B., Khotyaintsev, Y., Vaivads, A., Fazakerley, A., and Georgescu, E.: Observation of energetic electrons within magnetic islands, Nat. Phys, 4, 19-23, doi:10.1038/Nphys777, 2008.

Daughton, W., Scudder, J., and Karimabadi, H.: Fully kinetic simulations of undriven magnetic reconnection with open boundary conditions, Phys. Plasmas, 13, 072101, doi:10.1063/1.2218817, 2006.

Daughton, W., Roytershteyn, V., Karimabadi, H., Yin, L., Albright, B. J., Bergen, B., and Bowers, K. J.: Role of electron physics in the development of turbulent magnetic reconnection in collisionless plasmas, Nat. Phys., 7, 539-542, doi:10.1038/nphys1965, 2011.

Deng, X. H., Matsumoto, H., Kojima, H., Mukai, T., Anderson, R. R., Baumjohann, W., and Nakamura, R.: Geotail encounter with reconnection diffusion region in the Earth's magnetotail: Evidence of multiple X lines collisionless reconnection?, J. Geophys. Res., 109, A05206, doi:10.1029/2003JA010031, 2004.

Divin, A. V., Sitnov, M. I., Swisdak, M., and Drake, J. F.: Reconnection onset in the magnetotail: Particle simulations with open boundary conditions, Geophys. Res. Lett., 34, L09109, doi:10.1029/2007GL029292, 2007.

Eastwood, J. P., Phan, T. D., Mozer, F. S., Shay, M. A., Fujimoto, M., Retino, A., Hesse, M., Balogh, A., Lucek, E. A., and Dandouras, I.: Multi-point observations of the Hall electromagnetic field and secondary island formation during magnetic reconnection, J. Geophys. Res., 112, A06235, doi:10.1029/2006JA012158, 2007.

Fu, H. S., Khotyaintsev, Y. V., André, M., and Vaivads, A.: Fermi and betatron acceleration of suprathermal electrons behind dipolarization fronts, Geophys. Res. Lett., 38, L16104, doi:10.1029/2011GL048528, 2011.

Ge, Y. S., Zhou, X.-Z., Liang, J., Raeder, J., Gilson, M. L., Donovan, E., Angelopoulos, V., and Runov, A.: Dipolarization fronts and associated auroral activities: 1. Conjugate observations and perspectives from global MHD simulations, J. Geophys. Res., 117, A10226, doi:10.1029/2012JA017676, 2012.

Gustafsson, G., André, M., Carozzi, T., Eriksson, A. I., Fälthammar, C.-G., Grard, R., Holmgren, G., Holtet, J. A., Ivchenko, N., Karlsson, T., Khotyaintsev, Y., Klimov, S., Laakso, H., Lindqvist, P.-A., Lybekk, B., Marklund, G., Mozer, F., Mursula, K., Pedersen, A., Popielawska, B., Savin, S., Stasiewicz, K., Tanskanen, P., Vaivads, A., and Wahlund, J.-E.: First results of electric field and density observations by Cluster EFW based on initial months of operation, Ann. Geophys., 19, 1219-1240, doi:10.5194/angeo19-1219-2001, 2001.

Henderson, P. D., Owen, C. J., Alexeev, I. V., Slavin, J., Fazakerley, A. N., Lucek, E., and Rème, H.: Cluster observations of flux rope structures in the near-tail, Ann. Geophys., 24, 651-666, doi:10.5194/angeo-24-651-2006, 2006.

Hones, E. W.: Substorm processes in the magnetotail: Comments on "On hot tenuous plasmas, fireballs, and boundary layers in the Earth's magnetotail” by Frank et al., J. Geophys. Res., 82, 5633-5643, 1977.

Huang, C., Lu, Q., Yang, Z., Wu, M., Dong, Q., and Wang, S.: The evolution of electron current sheet and formation of secondary islands in guide field reconnection, Nonlin. Processes Geophys., 18, 727-733, doi:10.5194/npg-18-727-2011, 2011.

Huang, C., Lu, Q. M., Zhang, H., Wu, M. Y., Dong, Q. L., Lu, S., and Wang, S.: Kinetic simulations of the structures of magnetic island in multiple $\mathrm{X}$ line guide field reconnection, Phys. Plasmas, 19, 042111, doi:10.1063/1.4704799, 2012.

Ieda, A., Machida, S., Mukai, T., Saito, Y., Yamamoto, T., Nishida, A., Terasawa, T., and Kokubun, S.: Statistical analysis of the plasmoid evolution with Geotail observations, J. Geophys. Res., 103, 4453-4466, 1998.

Imada, S., Nakamura, R., Daly, P. W., Hoshino, M., Baumjohann, W., Muhlbachler, S., Balogh, A., and Rème, H.: Energetic electron acceleration in the downstream reconnection outflow region, J. Geophys. Res., 112, A03202, doi:10.1029/2006JA011847, 2007.

Imber, S. M., Slavin, J. A., Auster, H. U., and Angelopoulos, V.: A THEMIS survey of flux ropes and traveling compression regions: Location of the near-Earth reconnection site during solar minimum, J. Geophys. Res., 116, A02201, doi:10.1029/2010JA016026, 2011.

Johnstone, A. D., Alsop, C., Burge, S., Carter, P. J., Coates, A. J., Coker, A. J., Fazakerley, A. N., Grande, M., Gowen, R. A., Gurgiolo, C., Hancock, B. K., Narheim, B., Preece, A., Sheather, P. H., Winningham, J. D., and Woodliffe, R. D.: Peace: A plasma electron and current experiment, Space Sci. Rev., 79, 351-398, doi:10.1023/A:1004938001388, 1997.

Kiehas, S. A., Angelopoulos, V., Runov, A., Moldwin, M. B., and Möstl, C.: On the formation of tilted flux ropes in the Earth's magnetotail observed with ARTEMIS, J. Geophys. Res., 117, A05231, doi:10.1029/2011JA017377, 2012.

Kiehas, S. A., Angelopoulos, V., Runov, A., and Li, S.-S.: On the azimuthal size of flux ropes near lunar orbit, J. Geophys. Res., 118, 4415-4424, doi:10.1002/jgra.50425, 2013.

Lee, L. C. and Fu, Z. F.: A theory of magnetic flux transfer at the Earth's magnetopause, Geophys. Res. Lett., 12, 105-108, doi:10.1029/GL012i002p00105, 1985. 
Lepping, R. P., Jones, J. A., and Burlaga, L. F.: Magnetic field structure of interplanetary magnetic clouds at 1 AU, J. Geophys. Res., 95, 11957-11965, doi:10.1029/JA095iA08p11957, 1990.

Lui, A. T. Y., Dunlop, M. W., Rème, H., Kistler, L. M., Gustafsson, G., and Zong, Q.-G.: Internal structure of a magnetic flux rope from Cluster observations, Geophys. Res. Lett., 34, L07102, doi:10.1029/2007GL029263, 2007.

Nakamura, R., Baumjohann, W., Klecker, B., Bogdanova, Y., Balogh, A., Rème, H., Bosqued, J. M., Dandouras, I., Sauvaud, J. A., Glassmeier, K. H., Kistler, L., Mouikis, C., Zhang, T. L., Eichelberger, H., and Runov, A.: Motion of the dipolarization front during a flow burst event observed by Cluster, Geophys Res. Lett., 29, 1942, doi:10.1029/2002gl015763, 2002.

Nakamura, R., Baumjohann, W., Asano, Y., Runov, A., Balogh, A., Owen, C. J., Fazakerley, A. N., Fujimoto, M., Klecker, B., and Rème, H.: Dynamics of thin current sheets associated with magnetotail reconnection, J. Geophys. Res., 111, A11206, doi:10.1029/2006ja011706, 2006.

Nakamura, R., Baumjohann, W., Fujimoto, M., Asano, Y., Runov, A., Owen, C. J., Fazakerley, A. N., Klecker, B., Rème, H., Lucek, E. A., Andre, M., and Khotyaintsev, Y.: Cluster observations of an ion-scale current sheet in the magnetotail under the presence of a guide field, J. Geophys. Res., 113, A07s16, doi:10.1029/2007ja012760, 2008.

Ohtani, S., Shay, M. A., and Mukai, T.: Temporal structure of the fast convective flow in the plasma sheet: Comparison between observations and two-fluid simulations, J. Geophys. Res., 109, A03210, doi:10.1029/2003JA010002, 2004.

Rème, H., Aoustin, C., Bosqued, J. M., Dandouras, I., Lavraud, B., Sauvaud, J. A., Barthe, A., Bouyssou, J., Camus, Th., Coeur-Joly, O., Cros, A., Cuvilo, J., Ducay, F., Garbarowitz, Y., Medale, J. L., Penou, E., Perrier, H., Romefort, D., Rouzaud, J., Vallat, C., Alcaydé, D., Jacquey, C., Mazelle, C., d’Uston, C., Möbius, E., Kistler, L. M., Crocker, K., Granoff, M., Mouikis, C., Popecki, M., Vosbury, M., Klecker, B., Hovestadt, D., Kucharek, H., Kuenneth, E., Paschmann, G., Scholer, M., Sckopke, N., Seidenschwang, E., Carlson, C. W., Curtis, D. W., Ingraham, C., Lin, R. P., McFadden, J. P., Parks, G. K., Phan, T., Formisano, V., Amata, E., Bavassano-Cattaneo, M. B., Baldetti, P., Bruno, R., Chionchio, G., Di Lellis, A., Marcucci, M. F., Pallocchia, G., Korth, A., Daly, P. W., Graeve, B., Rosenbauer, H., Vasyliunas, V., McCarthy, M., Wilber, M., Eliasson, L., Lundin, R., Olsen, S., Shelley, E. G., Fuselier, S., Ghielmetti, A. G., Lennartsson, W., Escoubet, C. P., Balsiger, H., Friedel, R., Cao, J.-B., Kovrazhkin, R. A., Papamastorakis, I., Pellat, R., Scudder, J., and Sonnerup, B.: First multispacecraft ion measurements in and near the Earth's magnetosphere with the identical Cluster ion spectrometry (CIS) experiment, Ann. Geophys., 19, 1303-1354, doi:10.5194/angeo19-1303-2001, 2001.

Retinò, A., Nakamura, R., Vaivads, A., Khotyaintsev, Y., Hayakawa, T., Tanaka, K., Kasahara, S., Fujimoto, M., Shinohara, I., Eastwood, J. P., Andre, M., Baumjohann, W., Daly, P. W., Kronberg, E. A., and Cornilleau-Wehrlin, N.: Cluster observations of energetic electrons and electromagnetic fields within a reconnecting thin current sheet in the Earth's magnetotail, J. Geophys. Res., 113, A12215 doi:10.1029/2008ja013511, 2008.

Runov, A., Voronkov, I., Asano, Y., Baumjohann, W., Fujimoto, M., Nakamura, R., Takada, T., Volwerk, M., Vörös, Z., Meurant, M., Fazakerley, A., Rème, H., and Balogh, A.: Structure of the near-
Earth plasma sheet during tailward flows, Ann. Geophys., 26, 709-724, doi:10.5194/angeo-26-709-2008, 2008.

Runov, A., Angelopoulos, V., Sitnov, M. I., Sergeev, V. A., Bonnell, J., McFadden, J. P., Larson, D., Glassmeier, K.H., and Auster, U.: THEMIS observations of an earthwardpropagating dipolarization front, Geophys. Res. Lett., 36, L14106, doi:10.1029/2009GL038980, 2009.

Runov, A., Angelopoulos, V., Zhou, X.-Z., Zhang, X.-J., Li, S., Plaschke, F., and Bonnell, J.: A THEMIS multicase study of dipolarization fronts in the magnetotail plasma sheet, J. Geophys. Res., 116, A05216, doi:10.1029/2010JA016316, 2011 a.

Runov, A., Angelopoulos, V., Sitnov, M., Sergeev, V. A., Nakamura, R., Nishimura, Y., Frey, H. U., McFadden, J. P., Larson, D., Bonnell, J., Glassmeier, K. H., Auster, U., Connors, M., Russell, C. T., and Singer, H. J.: Dipolarization fronts in the magnetotail plasma sheet, Planet Space Sci., 59, 517-525, doi:10.1016/j.pss.2010.06.006, 2011b.

Schindler, K.: A theory of the substorm mechanism, J. Geophys. Res., 79, 2803-2810, doi:10.1029/JA079i019p02803, 1974.

Schmid, D., Volwerk, M., Nakamura, R., Baumjohann, W., and Heyn, M.: A statistical and event study of magnetotail dipolarization fronts, Ann. Geophys., 29, 1537-1547, doi:10.5194/angeo29-1537-2011, 2011.

Sergeev, V., Elphic, R. C., Mozer, F. S., Saint-Marc, A., and Sauvaud, J.-A.: A two-satellite study of nightside flux transfer events in the plasma sheet, Planet. Space Sci., 40, 1551-1572, 1992.

Sharma, A. S., Nakamura, R., Runov, A., Grigorenko, E. E., Hasegawa, H., Hoshino, M., Louarn, P., Owen, C. J., Petrukovich, A., Sauvaud, J.-A., Semenov, V. S., Sergeev, V. A., Slavin, J. A., Sonnerup, B. U. Ö., Zelenyi, L. M., Fruit, G., Haaland, S., Malova, H., and Snekvik, K.: Transient and localized processes in the magnetotail: a review, Ann. Geophys., 26, 9551006, doi:10.5194/angeo-26-955-2008, 2008.

Sitnov, M. I., Swisdak, M., and Divin, A. V.: Dipolarization fronts as a signature of transient reconnection in the magnetotail, J. Geophys. Res., 114, A04202, doi:10.1029/2008JA013980, 2009.

Slavin, J. A., Smith, E. J., Tsurutani, B. T., Sibeck, D. G., Singer, H. J., Baker, D. N., Gosling, J. T., Hones, E. W., and Scarf, F. L.: Substorm associated traveling compression regions in the distant tail: Isee3 Geotail observations, Geophys. Res. Lett., 11, 657660, doi:10.1029/GL011i007p00657, 1984.

Slavin, J. A., Fairfield, D. H., Kuznetsova, M. M., Owen, C. J., Lepping, R. P., Taguchi, S., Mukai, T., Saito, Y., Yamamoto, T., Kokubun, S., Lui, A. T. Y., and Reeves, G. D.: ISTP observations of plasmoid ejection: IMP 8 and Geotail, J. Geophys. Res., 103, 119-134, 1998.

Slavin, J. A., Lepping, R. P., Gjerloev, J., Fairfield, D. H., Hesse, M., Owen, C. J., Moldwin, M. B., Nagai, T., Ieda, A., and Mukai, T.: Geotail observations of magnetic flux ropes in the plasma sheet, J. Geophys. Res., 108, 1015, doi:10.1029/2002JA009557, 2003.

Sonnerup, B. and Schneible, M.: Minimum and maximum variance analysis, in: Analysis Methods for Multi-Spacecraft Data, edited by: Paschmann, G. and Daly, P., 185-220, ESA, Noordwijk, 1998.

Sormakov, D. A. and Sergeev, V. A.: Topology of magnetic flux ropes in the magnetospheric plasma sheet as measured by the Geotail spacecraft, Cosmic Res., 46, 387-391, 2008. 
Steed, K., Owen, C. J., Harra, L. K., Green, L. M., Dasso, S., Walsh, A. P., Démoulin, P., and van Driel-Gesztelyi, L.: Locating the solar source of 13 April 2006 magnetic cloud, Ann. Geophys., 26, 3159-3168, doi:10.5194/angeo-26-3159-2008, 2008.

Teh, W. L., Eriksson, S. Sonnerup, B. U. Ö., Ergun, R., Angelopoulos, V., Glassmeier, K. H., McFadden, J. P., and Bonnell, J. W.: THEMIS observations of a secondary magnetic island within the Hall electromagnetic field region at the magnetopause, Geophys. Res. Lett., 37, L21102, doi:10.1029/2010GL045056, 2010.

Wang, R. S., Lu, Q. M., Guo, J., and Wang, S.: Spatial distribution of energetic electrons during magnetic reconnection, Chin. Phys. Lett., 25, 3083-3085, doi:10.1088/0256-307X/25/8/093, 2008.

Wang, R. S., Lu, Q., Du, A., and Wang, S.: In situ observations of a secondary magnetic island in an ion diffusion region and associated energetic electrons, Phys. Rev. Lett., 104, 175003, doi:10.1103/PhysRevLett.104.175003, 2010a.

Wang, R. S., Lu, Q., Li, X., Huang, C., and Wang, S.: Observations of energetic electrons up to $200 \mathrm{keV}$ associated with a secondary island near the center of an ion diffusion region: A Cluster case study, J. Geophys. Res., 115, A11201, doi:10.1029/2010JA015473, 2010b.

Wang, R. S., Nakamura, R., Lu, Q. M., Du, A. M., Zhang, T. L., Baumjohann, W., Khotyaintsev, Y. V., Volwerk, M., Andre, M., Fujimoto, M., Nakamura, T. K. M., Fazakerley, A. N., Du, J., Teh, W., Panov, E. V., Zieger, B., Pan, Y. X., and Lu, S.: Asymmetry in the current sheet and secondary magnetic flux ropes during guide field magnetic reconnection, J. Geophys. Res., 117, A07223, doi:10.1029/2011ja017384, 2012.
Wang, Yuming, Caixia Chen, Bin Gui, Chenglong Shen, Pinzhong Ye, and Wang, S.: Statistical Study of Coronal Mass Ejection Source Locations: Understanding CMEs Viewed in Coronagraphs, J. Geophys. Res., 116, A04104, doi:10.1029/2010JA016101, 2011.

Wilken, B., Daly, P. W., Mall, U., Aarsnes, K., Baker, D. N., Belian, R. D., Blake, J. B., Borg, H., Büchner, J., Carter, M., Fennell, J. F., Friedel, R., Fritz, T. A., Gliem, F., Grande, M., Kecskemety, K., Kettmann, G., Korth, A., Livi, S., McKenna-Lawlor, S., Mursula, K., Nikutowski, B., Perry, C. H., Pu, Z. Y., Roeder, J., Reeves, G. D., Sarris, E. T., Sandahl, I., Søraas, F., Woch, J., and Zong, Q.-G.: First results from the RAPID imaging energetic particle spectrometer on board Cluster, Ann. Geophys., 19, 1355-1366, doi:10.5194/angeo-19-1355-2001, 2001.

Wu, M. Y., Lu, Q. M., Volwerk, M., Voros, Z., Zhang, T. L., Shan, L. C., and Huang, C.: A statistical study of electron acceleration behind the dipolarization fronts in the magnetotail, J. Geophys. Res., 118, 1-7, doi:10.1002/jgra.50456, 2013.

Xiao C. J., Pu, Z. Y., Ma, Z. W., Fu, S. Y., Huang, Z. Y., and Zong, Q. G.: Inferring of Flux Rope Axis with Cluster Measurements at the Magnetopause, J. Geophys. Res., 109, A11218, doi:10.1029/2004JA010594, 2004.

Zong, Q.-G., Fu, S. Y., Baker, D. N., Goldstein, M. L., Song, P., Slavin, J. A., Fritz, T. A., Cao, J. B., Amm, O., Frey, H., Korth, A., Daly, P. W., Reme, H., and Pedersen, A., Earthward flowing plasmoid: Structure and its related ionospheric signature, J. Geophys. Res., 112, A07203, doi:10.1029/2006JA012112, 2007. 